"Predetermined Interest Rates in a Analytical RBC model"

Patrick Fève, Alban Moura and Olivier Pierrard 


\title{
PREDETERMINED INTEREST RATES IN AN ANALYTICAL RBC MODEL
}

\author{
PATRICK FÈVE, ALBAN MOURA, AND OLIVIER PIERRARD
}

\begin{abstract}
We solve a version of the analytical Real Business Cycle (RBC) model with a predetermined rate of return on household saving. The solution differs from that of the benchmark RBC model along two dimensions: (i) Policy functions depend on the variance of the technology shock. (ii) There is a suboptimal pattern of excess saving. We discuss the economic intuition underlying these properties. We also demonstrate that unconditional welfare can be higher in the suboptimal model with predetermined interest rates, providing a clear illustration of the pitfall with unconditional welfare comparisons.
\end{abstract}

JEL Codes: E21, E32, E43.

Keywords: RBC model, predetermined interest rates, over-saving, conditional and unconditional welfare.

\section{INTRODUCTION}

Following the landmark contributions from Bernanke, Gertler, and Gilchrist (1999, BGG hereafter), Iacoviello (2005), or Gertler and Karadi (2011), dynamic stochastic general equilibrium (DSGE) models with financial frictions often impose rates of return for lenders that are predetermined and do not respond instantaneously to the aggregate state of the economy. This assumption is usually introduced without much discussion, suggesting that the literature views it as a benign premise. However, recent work by Dmitriev and Hoddenbagh (2017) shows that it may be important, since removing predetermined lending rates from the BGG model considerably weakens the financial accelerator.

Patrick Fève: Toulouse School of Economics and Université Toulouse 1 - Capitole, 21 allée de Brienne, 31000 Toulouse, France (patrick.feve@tse-fr.eu). Alban Moura: Banque centrale du Luxembourg, Département Économie et Recherche, 2 boulevard Royal, L-2983 Luxembourg (e-mail: alban.moura@bcl.lu). Olivier Pierrard: Banque centrale du Luxembourg, Département Économie et Recherche, 2 boulevard Royal, L-2983 Luxembourg (e-mail: olivier.pierrard@bcl.lu). For helpful comments, we thank Fabrice Collard, Mikhail Dmitriev, Pablo Garcia, and Paolo Guarda, as well as participants at a BCL internal seminar. This paper has been produced in the context of the partnership agreement between the BCL and TSE. It should not be reported as representing the views of the Banque centrale du Luxembourg or the Eurosystem. The views expressed are those of the authors and may not be shared by other research staff or policymakers at BCL or the Eurosystem. 
In this note, we shed light on the implications of predetermined interest rates by introducing them in a well-known framework: the Real Business Cycle (RBC) model. To clarify the intuitions and avoid inaccuracies due to approximation techniques, we study the model under conditions that guarantee a closed-form solution (log utility on consumption, Cobb-Douglas technology, and full capital depreciation).

We find that predetermined rates affect the model equilibrium along two dimensions. First, the policy functions in the economy with predetermined rates depend on the variance of the technology shock. We provide a condition for a bounded solution to exist. In contrast, policy functions do not depend on the shock variance in the standard RBC model.

Second, the saving rate is higher in the economy with predetermined rates than in the RBC model. Since the latter features an efficient allocation, we conclude that predetermined lending rates are associated with inefficient over-saving. We appeal to standard results from finance theory to interpret this association. Intuitively, the return to capital covaries positively with consumption in the RBC model, which destabilizes the consumption path and makes saving less attractive for risk-averse households. On the other hand, rates of return are not correlated with future consumption when they are predetermined, so that households have a larger incentive to save. Importantly, over-saving does not occur because of precautionary behavior in the environment with predetermined rates, since saving decisions are risk free.

Finally, we demonstrate that unconditional (average) welfare can be higher in the model with predetermined rates than in the RBC economy, depending on the variance of the shock. Since the RBC equilibrium is a Pareto optimum, our analytical framework illustrates in a transparent fashion the pitfall with unconditional welfare comparisons when the social utility function includes time discounting. ${ }^{1}$

\section{The Models}

In this section, we review the standard $\mathrm{RBC}$ model and introduce an alternative economy with predetermined interest rates. The two models differ only in the timing of events in the capital market. Indeed, while the rate of return on current saving must be forecast in the RBC model, we assume that institutions require the firm to promise a known rate of return in the alternative economy.

2.1. The RBC model. We consider a decentralized economy with a representative household and a representative firm.

\footnotetext{
${ }^{1}$ See, e.g., Kim, Kim, Schaumburg, and Sims (2008) and Kim and Kim (2018) for discussions of unconditional welfare comparisons.
} 
The representative household has preferences given by $E_{0} \sum_{t=0}^{\infty} \beta^{t} \ln \left(c_{t}\right)$, where $E_{0}$ is the expectation operator conditional on date- 0 information, $\beta \in[0,1[$ is the discount factor, and $c_{t}$ denotes consumption. At each period, the household receives income from past saving and corporate profits $\pi_{t}$, and allocates expenditures between consumption and capital $k_{t}$. With full capital depreciation, the budget constraint verifies $c_{t}+k_{t}=r_{t}^{k} k_{t-1}+\pi_{t}$, where $r_{t}^{k}$ denotes the state-contingent return on capital. At each period, the optimal consumption-saving plan is characterized by the Euler equation $1=\beta E_{t}\left(r_{t+1}^{k} c_{t} / c_{t+1}\right)$.

At date $t$, the representative firm uses the $k_{t-1}$ available units of capital to produce the final good in quantity $y_{t}=\epsilon_{t} k_{t-1}^{\alpha}$, where $\left.\alpha \in\right] 0,1\left[\right.$ and $\epsilon_{t}$ is a stochastic technology process evolving according to $\epsilon_{t}=\epsilon_{t-1}^{\rho} \exp \left(u_{t}\right)$, with $\rho \in\left[0,1\left[, u_{t} \sim N\left(0, \sigma^{2}\right)\right.\right.$, and $\sigma \geq 0$. Corporate profits are given by $\pi_{t}=\epsilon_{t} k_{t-1}^{\alpha}-r_{t}^{k} k_{t-1}$ and the optimal production plan verifies $\alpha \epsilon_{t} k_{t-1}^{\alpha-1}=r_{t}^{k}$.

Finally, the aggregate resource constraint is $c_{t}+k_{t}=\epsilon_{t} k_{t-1}^{\alpha}$.

After rearranging, the equilibrium system becomes

$$
\left\{\begin{array}{l}
1 / c_{t}=\alpha \beta E_{t}\left(\epsilon_{t+1} k_{t}^{\alpha-1} / c_{t+1}\right) \\
c_{t}+k_{t}=\epsilon_{t} k_{t-1}^{\alpha} \\
\epsilon_{t}=\epsilon_{t-1}^{\rho} \exp \left(u_{t}\right)
\end{array}\right.
$$

As is well known (McCallum, 1988), System (1) admits an exact solution.

Proposition 1. The analytical RBC model (1) has the closed-form solution

$$
(R B C)\left\{\begin{aligned}
\epsilon_{t} & =\epsilon_{t-1}^{\rho} \exp \left(u_{t}\right), \\
k_{t} & =\alpha \beta \epsilon_{t} k_{t-1}^{\alpha}, \\
c_{t} & =(1-\alpha \beta) \epsilon_{t} k_{t-1}^{\alpha} .
\end{aligned}\right.
$$

2.2. The model with predetermined interest rates. The alternative model is identical to the RBC economy, with two exceptions. First, we assume that the firm needs to borrow capital from the household at date $t$ in order to produce at date $t+1$. Second, the firm and the household cannot write state-contingent contracts, so that the return to capital has to be predetermined with respect to the state of the economy. These two assumptions can be interpreted as reflecting unmodeled institutional frictions, for instance arising from financial intermediation. ${ }^{2}$

In this alternative model, the household's budget constraint becomes $c_{t}+k_{t}=(1+$ $\left.r_{t-1}^{d}\right) k_{t-1}+\pi_{t}$, where $r_{t-1}^{d}$ is the predetermined return on capital. The implied Euler

\footnotetext{
${ }^{2}$ As we emphasized in the introduction, DSGE models with financial intermediation typically embed predetermined rates of return on household saving. Additional examples include Gerali, Neri, Sessa, and Signoretti (2010), Kollmann, Enders, and Müller (2011), and Iacoviello (2015).
} 
equation is then $1=\beta\left(1+r_{t}^{d}\right) E_{t}\left(c_{t} / c_{t+1}\right)$. Notice how our alternative timing assumption allows us to extract the rate of return from the conditional expectation.

On the firm's side, the profit-maximizing problem becomes dynamic as the cost of next period's capital is fixed at date $t$. The expected profit function is $E_{t} \pi_{t+1}=E_{t} \epsilon_{t+1} k_{t}^{\alpha}-$ $\left(1+r_{t}^{d}\right) k_{t}$ and the optimality condition implies $r_{t}^{d}=\alpha E_{t}\left(\epsilon_{t+1} k_{t}^{\alpha-1}\right)-1 .^{3}$

After rearranging, the equilibrium system becomes

$$
\left\{\begin{array}{l}
1 / c_{t}=\alpha \beta E_{t}\left(\epsilon_{t+1} k_{t}^{\alpha-1}\right) E_{t}\left(1 / c_{t+1}\right) \\
c_{t}+k_{t}=\epsilon_{t} k_{t-1}^{\alpha} \\
\epsilon_{t}=\epsilon_{t-1}^{\rho} \exp \left(u_{t}\right)
\end{array}\right.
$$

System (2) is very similar to System (1). The only difference lies in the Euler equation: the return to capital and the marginal utility of consumption at date $t+1$ now appear within separate expectation operators, which is not the case in the RBC model. As we show next, this is sufficient to significantly alter the properties of the economy. Under an additional assumption, System (2) also admits an exact solution.

Assumption 1. $\sigma^{2}<-\ln (\alpha \beta)$.

Proposition 2. Under Assumption 1, the model with predetermined interest rates (2) has the closed-form solution

$$
(P R E D)\left\{\begin{aligned}
\epsilon_{t} & =\epsilon_{t-1}^{\rho} \exp \left(u_{t}\right) \\
k_{t} & =\alpha \beta \bar{n} \epsilon_{t} k_{t-1}^{\alpha} \\
c_{t} & =(1-\alpha \beta \bar{n}) \epsilon_{t} k_{t-1}^{\alpha}
\end{aligned}\right.
$$

where $\bar{n}=\exp \left(\sigma^{2}\right) \geq 1$.

Proof. Using the properties of log-normal distributions, we rewrite the Euler equation in System (2) as

$$
\begin{aligned}
\frac{k_{t}}{c_{t}} & =\alpha \beta \exp \left(\sigma^{2} / 2\right) E_{t} \frac{\epsilon_{t}^{\rho} k_{t}^{\alpha}}{c_{t+1}}=\alpha \beta \exp \left(\sigma^{2} / 2\right) E_{t} \frac{\epsilon_{t+1} k_{t}^{\alpha}}{\exp \left(u_{t+1}\right) c_{t+1}} \\
& =\alpha \beta \exp \left(\sigma^{2} / 2\right) E_{t} \frac{c_{t+1}+k_{t+1}}{\exp \left(u_{t+1}\right) c_{t+1}}=\alpha \beta \exp \left(\sigma^{2}\right)+\alpha \beta \exp \left(\sigma^{2} / 2\right) E_{t} \frac{k_{t+1}}{\exp \left(u_{t+1}\right) c_{t+1}} .
\end{aligned}
$$

Iterating forward gives

$$
\frac{k_{t}}{c_{t}}=\gamma+\gamma^{2}+\gamma^{3}+\ldots+\gamma^{i}+\left[\alpha \beta \exp \left(\sigma^{2} / 2\right)\right]^{i} E_{t} \frac{k_{t+i} / c_{t+i}}{\prod_{j=1}^{i} \exp \left(u_{t+j}\right)}, i \geq 1,
$$

with $\gamma=\alpha \beta \bar{n}$ and $\bar{n}=\exp \left(\sigma^{2}\right)$. It is straightforward to show that when $\gamma<1$, the above expression converges to the solution in Proposition 2. On the other hand, when

\footnotetext{
${ }^{3}$ Risk-neutral pricing from the firm is required for predetermined interest rates to matter in general equilibrium. This can be micro-founded through an heterogeneous-agent setup. We thank Mikhail Dmitriev for raising this point.
} 
$\gamma \geq 1$, the series diverges and the economy collapses as optimal consumption reaches zero. Assumption 1 rules out this possibility.

The proposition shows that the model with predetermined rates differs from the RBC benchmark along three dimensions. First, the policy functions in Economy (PRED) depend on the variance of the technology shock through the term $\bar{n} \geq 1$. This is not the case in the RBC model. Second, the policy functions are only defined if the shocks are sufficiently small, in the sense of Assumption 1. This is reminiscent of results by Burnside (1998) or Collard, Fève, and Ghattassi (2006) showing that restrictions on the volatility of shocks may be necessary for a bounded equilibrium to exist when households are risk averse. Third, the saving rate is higher in Economy $(P R E D)$. In the next section, we elaborate on the economic intuition underlying these differences.

\section{Applications}

In this section, we use our analytical framework to make two points. First, we explain the pattern of over-saving in presence of predetermined interest rates by building on standard results from asset pricing. Second, we demonstrate that unconditional welfare can be higher in the model with predetermined interest rates than in the RBC economy, in spite of the RBC allocation being a Pareto optimum.

3.1. Predetermined rates and over-saving. As shown in Solution $(P R E D)$, the saving rate is higher in the economy with a predetermined rate of return than in the $\mathrm{RBC}$ model. The saving rate is also strictly increasing in the variance of the technology shock $\sigma^{2}$. This relationship appears to suggest a precautionary saving motive, but this is not the case since investment is risk free in the environment with predetermined rates. We actually show that the opposite is true: over-saving occurs because the return to investment is safe.

The intuition is best captured by comparing the marginal returns to saving in utility terms across the two models. From the Euler equations, we see that the marginal return to saving in utils is given by $E_{t} r_{k, t+1} / c_{t+1}$ in Model $(R B C)$ and by $E_{t}\left(r_{k, t+1}\right) E_{t}\left(1 / c_{t+1}\right)$ in Model $(P R E D)$. Using the covariance identity, we can also write the return in the RBC model as $\operatorname{Cov}_{t}\left(r_{k, t+1}, 1 / c_{t+1}\right)+E_{t}\left(r_{k, t+1}\right) E_{t}\left(1 / c_{t+1}\right)$. It is easy to spot that $\operatorname{Cov}_{t}\left(r_{k, t+1}, 1 / c_{t+1}\right)<0$ since the technology shock moves $r_{k, t+1}$ and $c_{t+1}$ in the same direction. It follows immediately that, along a given $\left(c_{t}, k_{t}, \epsilon_{t}\right)$ path, the return to saving is smaller in Model $(R B C)$ than in Model $(P R E D)$. This explains why the saving rate is higher in the model with predetermined interest rates.

Note that our argument only relies on the representative household being risk averse, since the marginal utility of consumption of a risk-neutral investor would be a constant 
that does not covary with the return to capital. On the other hand, we do not need the specific assumptions of $\log$ utility and full capital depreciation, which only appear for analytical convenience: with a CRRA utility function and incomplete depreciation, our argument would still imply that the return to saving in utils is larger with predetermined rates. Hence, we expect predetermined rates to generate over-saving in more general setups. ${ }^{4}$

Our previous discussion is a direct transposition of a standard result from the theory of consumption-based asset pricing. ${ }^{5}$ In its most frequent form, the result states that risk-averse investors prefer assets whose payoffs are negatively correlated with consumption growth, since they help smoothing consumption over time. The same logic applies here: while the return to capital is positively correlated with future consumption in Model $(R B C)$, the predetermined rate of return on saving is uncorrelated with it in Model $(P R E D)$, which makes saving and investment more desirable for the risk-averse household. The argument also explains why the saving rate is increasing with $\sigma$, since the hedge provided by the predetermined return is more valuable in a volatile economy.

3.2. A pitfall with unconditional welfare comparison. We now compare welfare across the Models $(R B C)$ and $(P R E D)$. Since allocations are optimal in the RBC model, we expect over-saving to be detrimental for welfare in the economy with predetermined interest rates. We show below that, while a measure of welfare that conditions on the state vector confirms this intuition, an unconditional metric finds higher welfare in Model (PRED).

We start by computing conditional welfare measures. Given a state vector $\left(\epsilon_{t}, k_{t-1}\right)$, conditional welfare in economy $i \in\{R B C, P R E D\}$ is just the value function of the representative household: $\mathcal{W}_{i}^{c}\left(\epsilon_{t}, k_{t-1}\right)=E_{t} \sum_{j=0}^{\infty} \beta^{j} \ln \left(c_{i, t+j}\right)$. Note that $\mathcal{W}_{R B C}^{c}$ is the social planner's objective function in the centralized version of the RBC economy. More generally, conditional welfare comparisons allow one to evaluate the models on equal footing by controlling for potential differences in long-run averages through a common initial condition.

Using the analytical solutions from Propositions 1 and 2, straightforward algebra leads to

$$
\mathcal{W}_{R B C}^{c}(\epsilon, k)=\frac{\ln (1-\alpha \beta)}{1-\beta}+\frac{\alpha \beta \ln (\alpha \beta)}{(1-\alpha \beta)(1-\beta)}+\frac{\ln (\epsilon)}{(1-\alpha \beta)(1-\beta \rho)}+\frac{\alpha \ln (k)}{1-\alpha \beta}
$$

\footnotetext{
${ }^{4}$ Indeed, our conclusions also hold in a 2-period model with CRRA utility and incomplete depreciation. ${ }^{5}$ See, e.g., Cochrane (2009, Chapter 1.4) for an excellent treatment.
} 
and

$$
\begin{aligned}
\mathcal{W}_{P R E D}^{c}(\epsilon, k) & =\frac{\ln (1-\alpha \beta \bar{n})}{1-\beta}+\frac{\alpha \beta \ln (\alpha \beta \bar{n})}{(1-\alpha \beta)(1-\beta)}+\frac{\ln (\epsilon)}{(1-\alpha \beta)(1-\beta \rho)}+\frac{\alpha \ln (k)}{1-\alpha \beta} \\
& =\mathcal{W}_{R B C}^{c}(\epsilon, k)+\frac{\ln \left(\frac{1-\alpha \beta \bar{n}}{1-\alpha \beta}\right)}{1-\beta}+\frac{\alpha \beta \ln (\bar{n})}{(1-\alpha \beta)(1-\beta)} .
\end{aligned}
$$

Thus conditional welfare does not depend on volatility in Model $(R B C)$, but does in Model $(P R E D)$ through the term $\bar{n}$. Moreover, since $\mathcal{W}_{R B C}^{c}=\mathcal{W}_{P R E D}^{c}$ when $\sigma=0$ and $\partial \mathcal{W}_{P R E D}^{c} / \partial \sigma \leq 0$, conditional welfare is higher in the RBC economy when there is uncertainty. Since allocations maximize $\mathcal{W}_{R B C}^{c}(\epsilon, k)$ in the $\mathrm{RBC}$ economy, this is an expected result.

We now turn to unconditional welfare, defined as the average value function of the representative household, $\mathcal{W}_{i}^{u}=E \mathcal{W}_{i}^{c}\left(\epsilon_{t}, k_{t-1}\right)$. Lester, Pries, and Sims (2014) argue that this unconditional metric is better than the conditional measure at capturing welfare differences in the long run, once the effects of initial conditions have vanished.

Since Models $(R B C)$ and $(P R E D)$ are both log-linear, simple computations reveal that

$$
\begin{aligned}
\mathcal{W}_{R B C}^{u} & =\frac{(1-\alpha) \ln (1-\alpha \beta)+\alpha \ln (\alpha \beta)}{(1-\alpha)(1-\beta)} \\
\mathcal{W}_{P R E D}^{u} & =\frac{(1-\alpha) \ln (1-\alpha \beta \bar{n})+\alpha \ln (\alpha \beta \bar{n})}{(1-\alpha)(1-\beta)} .
\end{aligned}
$$

It is straightforward to confirm that $\mathcal{W}_{R B C}^{u}=\mathcal{W}_{P R E D}^{u}$ when $\sigma=0$. In addition, $\partial \mathcal{W}_{P R E D}^{u} / \partial \sigma>0$ when $\bar{n}<1 / \beta, \partial \mathcal{W}_{P R E D}^{u} / \partial \sigma<0$ when $\bar{n}>1 / \beta$, and $\mathcal{W}_{P R E D}^{u} \rightarrow-\infty$ when $\bar{n} \rightarrow-\ln (\alpha \beta)$. Therefore, unconditional welfare is higher in Model $(P R E D)$ than in Model $(R B C)$ when shocks are relatively small.

This is a surprising result since the RBC allocation is efficient and preferred for any given state vector, or equivalently at any given point in time. The underlying logic is very close to the difference between the golden rule and the modified golden rule in the standard growth model. ${ }^{6}$ Intuitively, the representative household is indifferent between consuming more today or tomorrow at the RBC equilibrium. Moving to Model (PRED) implies higher saving today and more consumption in the long run, so that current consumption has to fall. This has to be detrimental for welfare if the agent is impatient, but the unconditional criterion neglects this transition effect by focusing only on long-run outcomes.

\footnotetext{
${ }^{6}$ See Kim and Kim (2018) for a discussion of the role of time preferences when comparing conditional and unconditional welfare.
} 


\section{Conclusion}

In this note, we solve an analytical Real Business Cycle (RBC) model with a predetermined rate of return on household saving. We demonstrate that equilibrium policy functions depend on the variance of the technology shock and that there is a suboptimal pattern of excess saving compared to the baseline model. We explain these properties using arguments from the theory of asset pricing. Our analytical framework also provides a clear illustration of the pitfall with unconditional welfare comparisons.

\section{REFERENCES}

Bernanke, B. S., M. Gertler, and S. Gilchrist (1999): "The Financial Accelerator in a Quantitative Business Cycle Framework," in Handbook of Macroeconomics, ed. by J. B. Taylor, and M. Woodford, vol. 1 of Handbook of Macroeconomics, chap. 21, pp. 1341-1393. Elsevier.

Burnside, C. (1998): "Solving Asset Pricing Models with Gaussian Shocks," Journal of Economic Dynamics and Control, 22(3), 329-340.

Cochrane, J. (2009): Asset Pricing: Revised Edition. Princeton University Press.

Collard, F., P. Fève, and I. Ghattassi (2006): "Predictability and Habit Persistence," Journal of Economic Dynamics and Control, 30(11), 2217-2260.

Dmitriev, M., and J. Hoddenbagh (2017): "The Financial Accelerator and the Optimal State-Dependent Contract," Review of Economic Dynamics, 24, 43-65.

Gerali, A., S. Neri, L. Sessa, and F. M. Signoretti (2010): "Credit and Banking in a DSGE Model of the Euro Area," Journal of Money, Credit and Banking, 42(s1), $107-141$

Gertler, M., And P. Karadi (2011): "A Model of Unconventional Monetary Policy," Journal of Monetary Economics, 58(1), 17-34.

IAcoviello, M. (2005): "House Prices, Borrowing Constraints, and Monetary Policy in the Business Cycle," American Economic Review, 95(3), 739-764.

(2015): "Financial Business Cycles," Review of Economic Dynamics, 18(1), $140-164$.

KIm, J., AND S. KIM (2018): "Conditional Versus Unconditional Utility as Welfare Criterion: Two Examples," Computational Economics, 51(3), 719-730.

Kim, J., S. Kim, E. Schaumburg, and C. A. Sims (2008): "Calculating and Using Second-Order Accurate Solutions of Discrete Time Dynamic Equilibrium Models," Journal of Economic Dynamics and Control, 32(11), 3397-3414.

Kollmann, R., Z. Enders, and G. J. Müller (2011): "Global Banking and International Business Cycles," European Economic Review, 55(3), 407-426. 
Lester, R., M. Pries, and E. Sims (2014): "Volatility and Welfare," Journal of Economic Dynamics and Control, 38(C), 17-36.

McCallum, B. T. (1988): "Real Business Cycle Models," NBER Working Papers 2480, National Bureau of Economic Research, Inc. 